\title{
Analysis of a Radioisotope Thermal Rocket Engine
}

\author{
Jonathan P. Machado-Rodriguez ${ }^{1}$ \\ University of Puerto Rico, Mayaguez, PR, 00680 \\ Geoffrey A. Landis ${ }^{2}$ \\ NASA Glenn Research Center, Cleveland, OH, 44135
}

\begin{abstract}
The Triton Hopper is a concept for a vehicle to explore the surface of Neptune's moon Triton, which uses a radioisotope heated rocket engine and in-situ propellant acquisition. The initial Triton Hopper conceptual design stores pressurized Nitrogen in a spherical tank to be used as the propellant. The aim of the research was to investigate the benefits of storing propellant at ambient temperature and heating it through a thermal block during engine operation, as opposed to storing gas at a high temperature. Lithium, lithium fluoride and beryllium were considered as possible materials for the thermal block. A heat energy analysis indicated that a lithium thermal mass would provide the highest heat energy for a temperature change from $900^{\circ} \mathrm{C}$ to $-100^{\circ} \mathrm{C}$. A heat transfer analysis was performed for Nitrogen at $-100^{\circ} \mathrm{C}$ flowing through 1000 passages inside a $1 \mathrm{~kg}$ lithium thermal block at a temperature of $900^{\circ} \mathrm{C}$. The system was analyzed as turbulent flow through a tube with constant surface temperature. The analysis indicated that the propellant reached a maximum temperature of $877^{\circ} \mathrm{C}$ before entering the nozzle. At this exit temperature, the average specific impulse $\left(I_{\mathrm{sp}}\right)$ of the engine was determined to be $157 \mathrm{~s}$. Previous studies for the stored heated gas concept suggest that the engine would have an average $I_{\text {sp }}$ of approximately $52 \mathrm{~s}$. Thus, the use of a thermal block concept results in a $200 \%$ engine performance increase. A tank sizing study was performed to determine if the concept is feasible in terms of mass requirements. The mass for a spherical carbon-fiber pressure vessel storing $35 \mathrm{~kg}$ of nitrogen at an initial temperature of $-100^{\circ} \mathrm{C}$ and a pressure of $1000 \mathrm{psia}$, was determined to be $7.2 \mathrm{~kg}$. The specific impulse analysis indicated that the maximum engine performance is obtained for a mass ratio of $5 \mathrm{~kg}$ of Nitrogen for every kilogram of lithium thermal mass. Thus, for $35 \mathrm{~kg}$ of Nitrogen the required thermal mass would be $7 \mathrm{~kg}$. This brings the total mass of the system to $49.2 \mathrm{~kg}$, which is less than the $56 \mathrm{~kg}$ landing payload capacity of the Triton Hopper. Finally, an insulation analysis using 10 $\mathrm{mm}$ of Multi-layer insulation indicated that a total of 22 watts of heat are lost to the environment. With the heat loss known, the power required to heat the thermal mass to $900^{\circ} \mathrm{C}$ in 24 days was determined to be 2.15 Watts. The study's results allowed us to conclude that the thermal mass concept is a better option for the Triton hopper propulsion, due to the performance increase provided, the low power requirement and its compliance with the landing mass requirement of the Triton Hopper.
\end{abstract}

\footnotetext{
${ }^{1}$ NASA Spring Intern, LEX0, Glenn Research Center, University of Puerto Rico - Mayaguez.

${ }^{2}$ Researcher, Photovoltaic and Electrochemical Systems Branch, NASA Glenn Research Center mailstop 302-1, 21000 Brookpark Road, Cleveland OH. AIAA Associate Fellow. 


\section{Nomenclature}

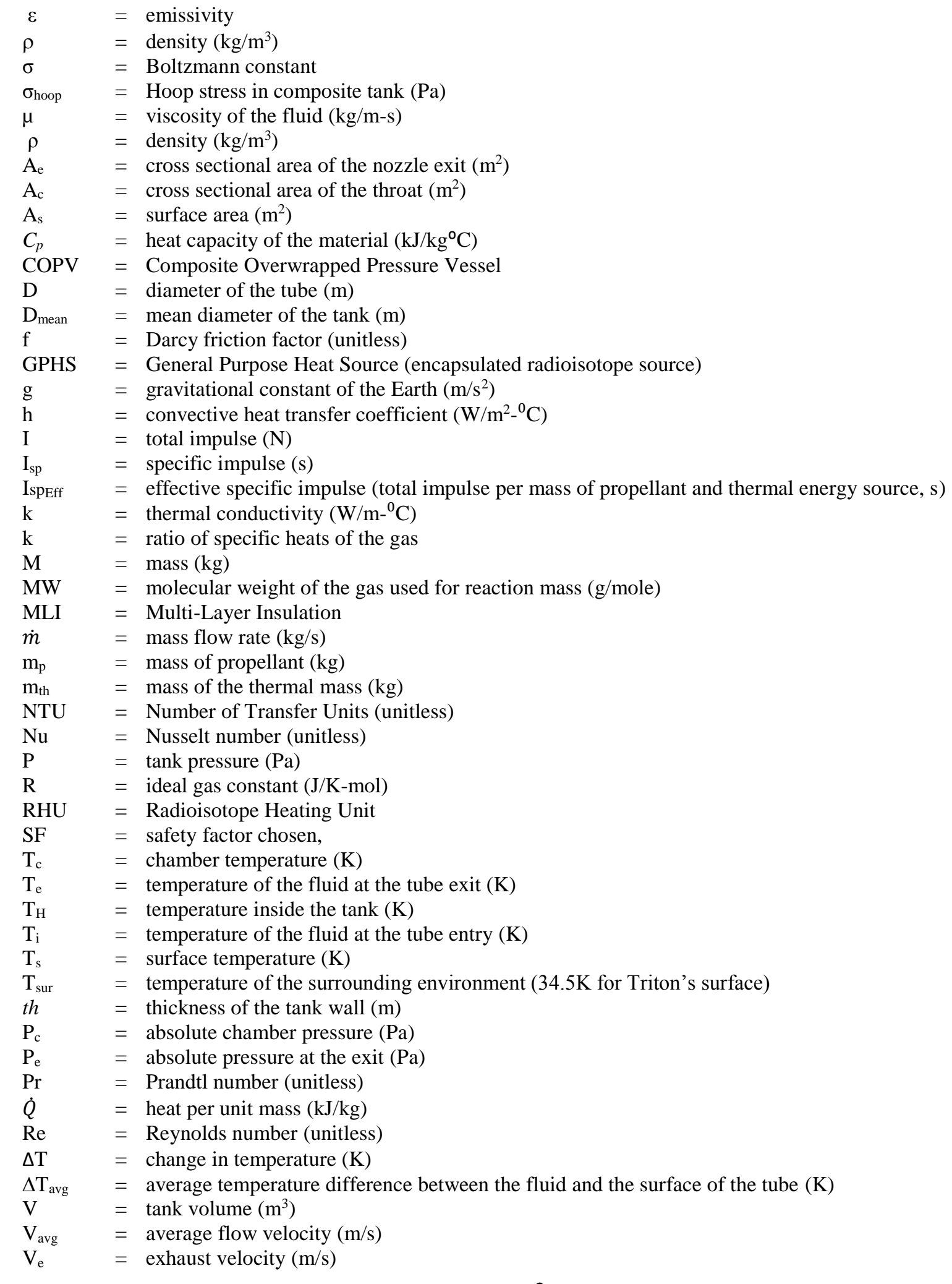




\section{Introduction}

$\mathrm{T}$

he Triton Hopper is a NASA Innovative Advanced concepts (NIAC) design study for a mobile vehicle to explore Neptune's largest moon Triton ${ }^{1-3}$. This celestial body was visited once by Voyager 2 in 1989, but it was only a fly-by mission. Triton is the only large moon in the solar system with a retrograde orbit, and because of this and its surface composition, it is believed to be a captured object from the Kuiper belt, a body similar to Pluto, but slightly larger. The Triton Hopper will use In-situ propellant acquisition to allow the vehicle to launch from the surface on a ballistic trajectory for the exploration across significant distances on the moon. It will gather frozen nitrogen from Triton's surface and store it in a tank for use as propellant. The engine for the Triton Hopper is powered by a radioisotope power system which will heat the propellant (as well as providing both electrical energy and thermal support to other components). The Triton Hopper would be the first ever vehicle to explore a Kuiper belt object. In addition, a vehicle that utilizes frozen gases as propellant would be revolutionary and would be a pathfinder for later designs to explore other celestial bodies. An artist's conception of the vehicle is shown in figure 1 below.

The propulsion system for the hopper is a radioisotope thermal thruster ${ }^{4-6}$. The baseline design analyzed in the conceptual design study stored nitrogen gas (acquired from surface deposits on Triton) in a tank heated to a temperature of $300 \mathrm{~K}$ (significantly above the ambient Triton surface temperature of $38 \mathrm{~K}$ ). The gas would then be expelled through the nozzle (a "cold gas thruster"). In-situ refueled radioisotope thermal engines have previously been proposed for a Mars hopper vehicle, refueled using atmospheric carbon dioxide as the reaction mass. ${ }^{7,8}$ The vehicle here uses in-situ nitrogen as the reaction mass.

The biggest disadvantage of the system is that it requires heavy pressurized gas tanks to store the heated nitrogen. The nitrogen cools as the tank blows down, which results in a decrease in performance. The propulsion system analyzed here consists of storing cold nitrogen in a spherical tank and passing it through a thermal block during engine operation, to heat the propellant to a desired temperature before it exits through the nozzle. Heating the gas as it flows through the system allows for higher gas temperatures at the exit, which provides a higher specific impulse, and reduces the tank weight by allowing the nitrogen propellant to be stored at higher density.

For the system analyzed, the reaction mass was nitrogen, since this can be acquired from nitrogen ice deposits found on the surface of Triton, allowing refueling of the vehicle from in-situ resources. Since specific impulse increases inversely with the square root of the molecular mass, a lower molecular mass propellant would produce higher performance. One possibility would be to use water, with a molecular mass of 18 , but water ice outcrops may not be available at all locations on Triton. Hydrogen, with a molecular mass of 2, provides the highest performance, but the challenges of refining hydrogen from local materials make it infeasable for locally-generated refueling.

The biggest challenge of the new concept is designing a system that provides enough heat to raise the nitrogen's temperature from $-100^{\circ} \mathrm{C}$ to $900^{\circ} \mathrm{C}$, while also being light enough to meet the mass requirements of the mission. A system like the one proposed requires a amount of high heat storage and high heat transfer rate. The thermal block can store energy either as thermal energy, utilizing its heat capacity, or in the form of latent heat, utilizing a phase change, and in the general case, will utilize both forms of energy storage.

Lithium, lithium fluoride and beryllium were the materials considered for use as the thermal mass. The following analysis presents the results for a heat storage capacity analysis and specific impulse analysis for the different thermal mass materials. The material that provides the best performance will be used to run a heat transfer analysis for the thermal block concept proposed. The purpose of the analysis is to determine if the material provides the high heat transfer rate needed to allow the propellant to reach the $900^{\circ} \mathrm{C}$ exit temperature. An insulation analysis is also performed in order to determine the amount of heat lost by the system. This will allow us to

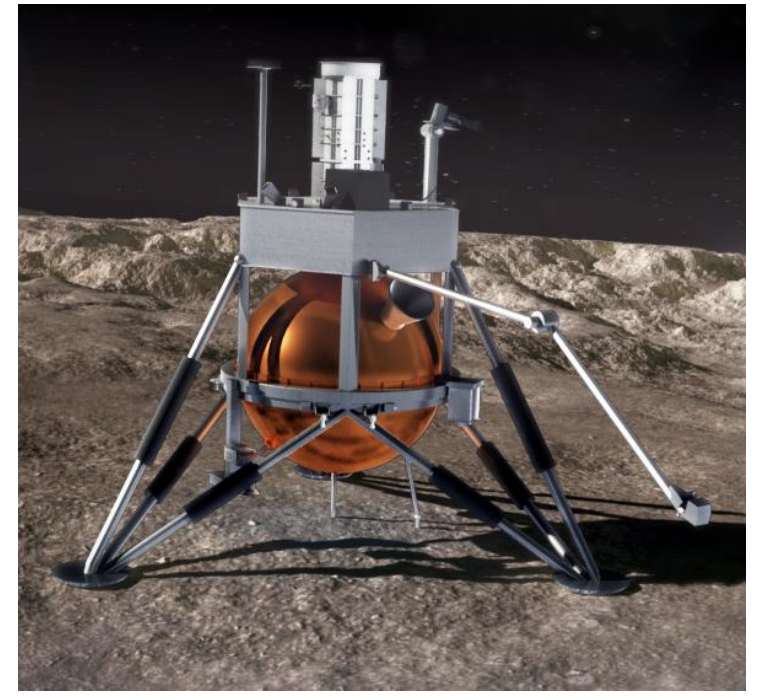

Fig. 1. Artist's conceptual of the Hopper vehicle refueling on the surface of Triton 
determine the amount of Radioisotope Heater Units (RHUs) or General Purpose Heat Source modules (GPHS) needed to heat the thermal mass.

\section{Thermal Block Material Analysis}

The radioisotope engine concept proposed requires a high heat storage capacity, and high heat transfer rate to achieve the desired exit temperature of the propellant. Lithium, lithium fluoride, and beryllium were considered as possible thermal block materials. Beryllium was chosen as a metal with both high thermal conductivity and high heat capacity, which stays solid over the entire operation temperature range of the thermal block ${ }^{9}$. A material such as beryllium that remains solid would eliminate the heat transfer reduction problems caused by the solidification of phase change materials used for the thermal block. Lithium was chosen as a metal which undergoes a phase change from liquid to solid over the temperature range of interest; this provides the advantage of a high heat capacity in both solid and liquid state, while also being the lightest of the materials considered ${ }^{9}$. Finally, lithium fluoride was chosen as the best case example of a phase change salt. This has both a high heat capacity and also a high heat of fusion at its melting point of $848^{\circ} \mathrm{C}$, although not as high thermal conductivity ${ }^{11}$. Several other materials, such as aluminum ${ }^{12}$ and copper ${ }^{13}$, were considered, but not chosen, due to poorer performance compared to the three material analyzed.

\section{A. Heat Energy}

The thermal energy released or absorbed per mass of substance is given by equation 1 .

$$
\dot{Q}=C_{p} \Delta T
$$

where $\dot{Q}$ is the amount of heat generated per mass of propellant $(\mathrm{kJ} / \mathrm{kg}), C_{p}$ is the heat capacity of the material $\left(\mathrm{kJ} / \mathrm{kg}-{ }^{\circ} \mathrm{C}\right)$ and $\Delta \mathrm{T}$ is the change in temperature $(\mathrm{K})$. The heat energy was calculated for a temperature change from $-100^{\circ} \mathrm{C}$ to $900^{\circ} \mathrm{C}$. This is shown in Fig. 2. The steps in the heat energy release show the temperatures at which thermal energy is released due to the release of the heat of fusion as the thermal mass transistions from liquid to solid.

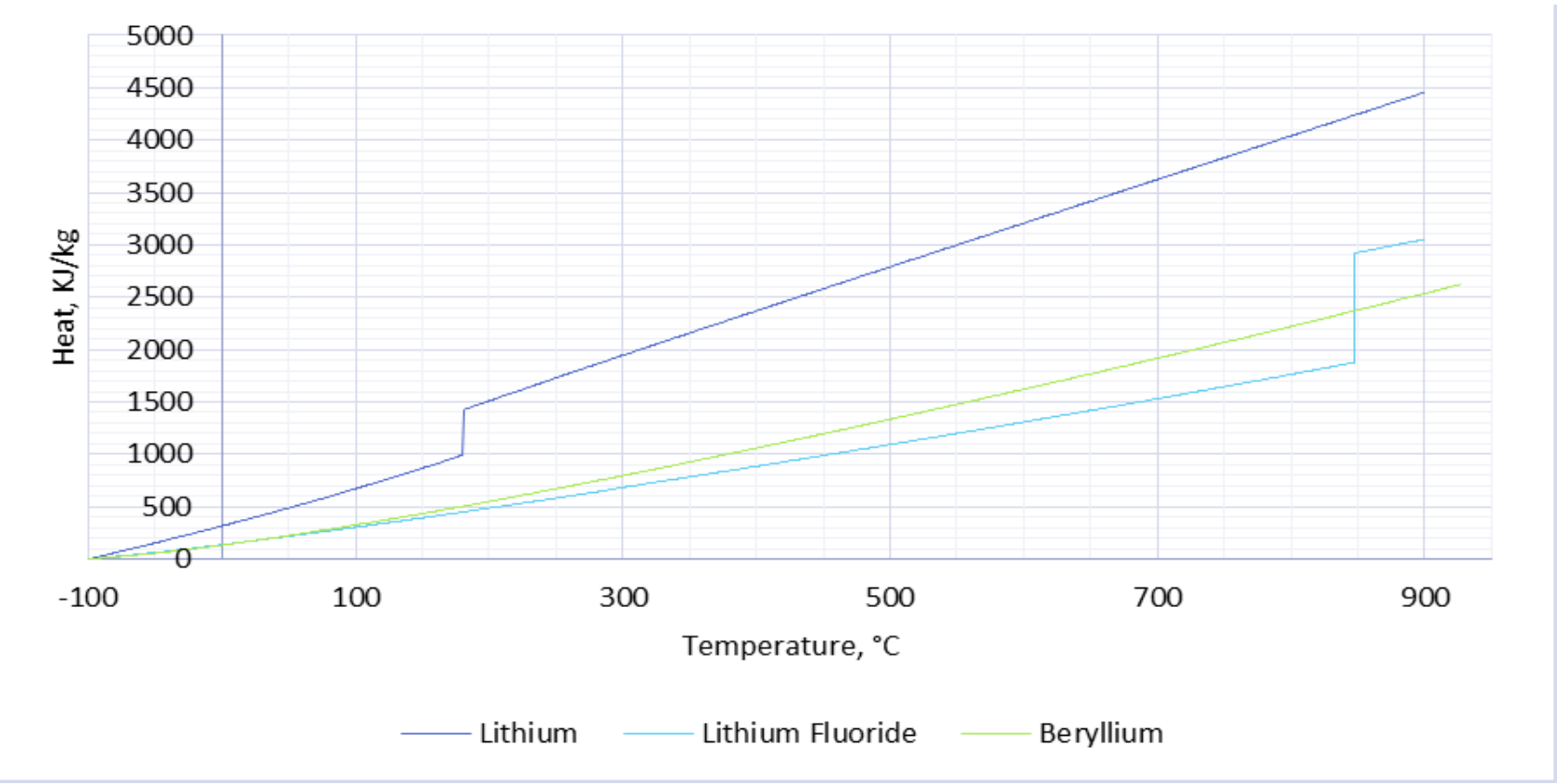

Figure 2. Heat energy of thermal block materials. The plot shows the amount of heat released or absorbed by the materials for a temperature range from $-100^{\circ} \mathrm{C}$ to $900^{\circ} \mathrm{C}$. The vertical segement for the curves of $\mathrm{Li}$ and $\mathrm{LiF}$ are the temperatures at which the materials release energy due to the phase change. 


\section{B. Specific Impulse}

Specific impulse $\left(I_{\mathrm{sp}}\right)$ describes how much thrust is delivered by an engine per propellant mass flow rate ${ }^{14,15}$. It is a measure of the efficiency of the engine and is given by equation 2 .

$$
I_{s p}=\frac{V_{e}}{g}
$$

where $I_{s p}$ is the specific impulse (s), $V_{e}$ is the exhaust velocity $(\mathrm{m} / \mathrm{s})$, and $g$ is the gravitational constant $\left(\mathrm{m} / \mathrm{s}^{2}\right)$. The exhaust velocity of the engine is determined ${ }^{15}$ from equation 3.

$$
\left.V_{e}=\sqrt{\frac{2 k R T_{c}}{M W(k-1)} *\left[1-\left(\frac{P_{e}}{P_{c}}\right)^{\frac{k-1}{k}}\right.}\right]+\frac{P_{e} A_{e}}{P_{c} A_{t}} * \sqrt{\frac{R T_{c}}{\left(k g_{c}\left(\frac{2}{k+1}\right)^{\frac{k+1}{k-1}}\right.}}
$$

where $\mathrm{V}_{\mathrm{e}}$ is the exhaust velocity in $\mathrm{m} / \mathrm{s}, \mathrm{k}$ is the ratio of specific heats of the gas, $\mathrm{R}$ is the ideal gas constant $(\mathrm{J} / \mathrm{K}$ $\mathrm{mol}), \mathrm{T}_{\mathrm{c}}$ is the chamber temperature $(\mathrm{K}), \mathrm{P}_{\mathrm{e}}$ is the absolute pressure at the exit $(\mathrm{Pa}), \mathrm{P}_{\mathrm{c}}$ is the absolute chamber pressure $(\mathrm{Pa}), \mathrm{A}_{\mathrm{e}}$ is the cross sectional area of the nozzle exit in $\mathrm{m}^{2}$, and $\mathrm{A}_{\mathrm{c}}$ is the cross sectional area of the throat $\left(\mathrm{m}^{2}\right)$. Assuming that the pressure at the exit of the nozzle is $\ll$ the pressure of the chamber, the exhaust velocity can be expressed as:

$$
V_{e}=\sqrt{\frac{2 k R T_{c}}{M W(k-1)}}
$$

where MW is the molecular weight of the gas, $26.98 \mathrm{~g} / \mathrm{mol}$ for Nitrogen.

The first step in determining the impulse generated by the engine is to determine the amount of nitrogen that needs to flow through $1 \mathrm{~kg}$ of thermal mass in order to reduce its temperature by $1^{\circ} \mathrm{C}$. This is given by equation 5 .

$$
\Delta m_{N 2}=C_{p} m_{t m} / \dot{Q}_{N 2}
$$

where $\Delta \mathrm{m}$ is the mass of Nitrogen in $\mathrm{kg}, C_{p}$ is the heat capacity of the heat reservoir material $\left(\mathrm{kJ} / \mathrm{kg}-{ }^{\circ} \mathrm{C}\right), \mathrm{m}_{\mathrm{tm}}$ is the mass of the thermal mass $(\mathrm{kg})$, and $\dot{Q}_{N 2}$ is the amount of heat per kilogram released or absorbed by Nitrogen for a change in temperature. The incremental impulse generated by the engine is determined by multiplying the exhaust velocity of the propellant by the mass of nitrogen required to reduce the temperature of 1 kilogram of material by 1 degree Celsius, according to the usual formula for total impulse

$$
I=m_{p} g I_{s p}=m_{p} V_{e}
$$

The plot in Fig. 3 show the impulse generated by the engine for the three different thermal block materials analyzed, for the ideal case where the heat transfer to the nitrogen is perfect (the non ideal case will be analyzed in the next section). 


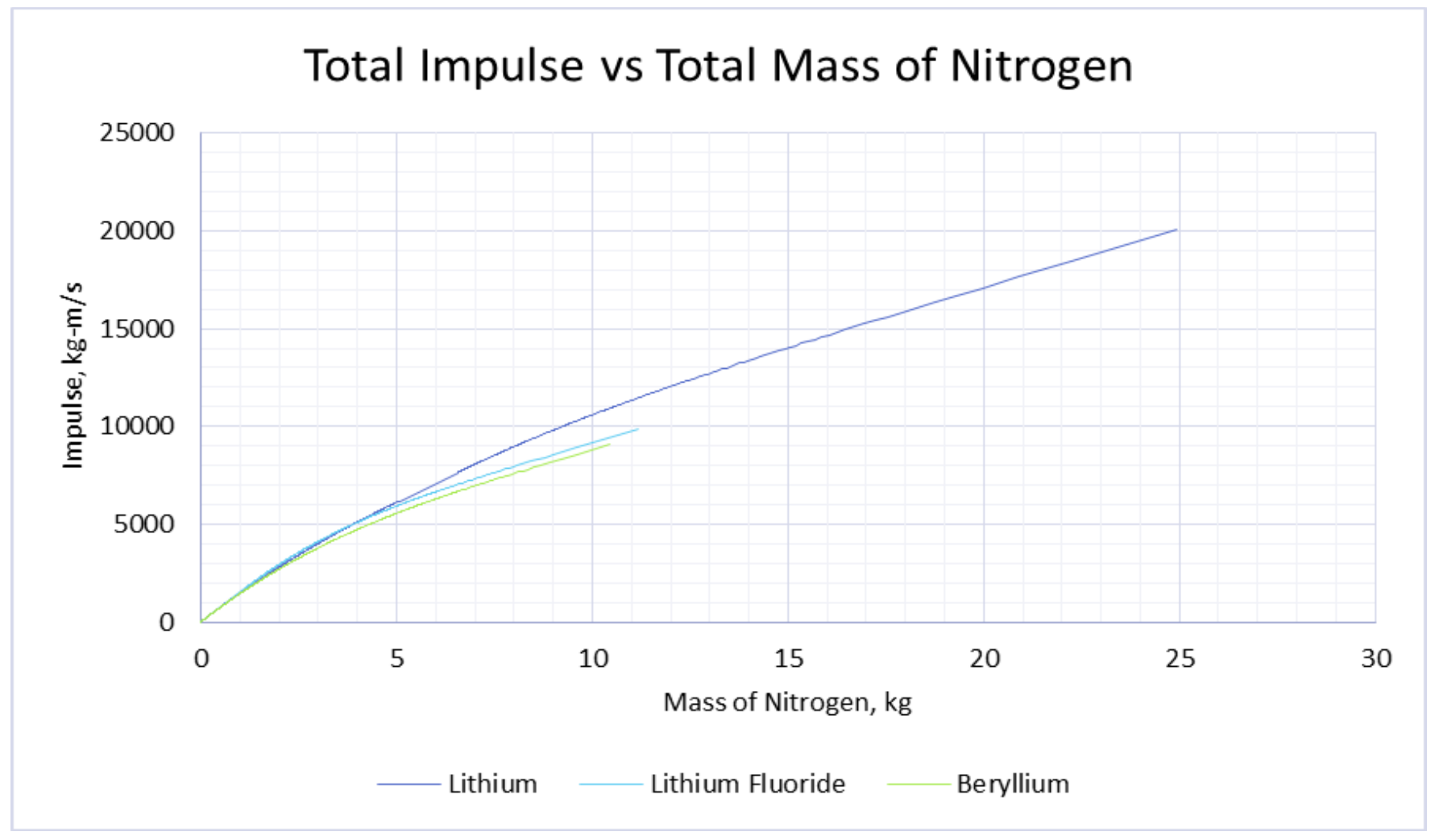

Figure 3. Total impulse vs. mass of nitrogen. The plot show the total impulse generated by the engine as a function of the amount of propellant mass sent through the one kilogram of thermal mass at an initial temperature of $900^{\circ} \mathrm{C}$, for the assumption of perfect heat transfer from the thermal block to the propellant.

The average specific impulse is defined as:

$$
I_{s p_{\text {avg }}}=\left(I / m_{N 2}\right) / g
$$

where $\mathrm{I}$ is the total impulse generated by the engine in $\mathrm{kg}-\mathrm{m} / \mathrm{s}, \mathrm{m}_{\mathrm{N} 2}$ is the mass of Nitrogen $(\mathrm{kg})$, and $\mathrm{g}$ is the gravitational constant $\left(\mathrm{m} / \mathrm{s}^{2}\right)$. The plot shown in Fig. 4 presents the average specific impulse generated by the engine over a change in temperature from $900^{\circ} \mathrm{C}$ to $-100^{\circ} \mathrm{C}$. The results indicate that the engine which uses a thermal block made of lithium would provide the best performance.

We define a term "effective" specific impulse, which takes into account the weight of the thermal mass as well as the reaction mass, and is a more accurate representation of the engine's performance. The plot shown in Fig. 5 presents the effective specific impulse generated by the engine for a change in temperature from $900^{\circ} \mathrm{C}$ to $-100^{\circ} \mathrm{C}$.

$$
I_{s p_{E f f}}=\left[I /\left(m_{N 2}+m_{t m}\right)\right] / g
$$

Again, this graph shows theoretical specific impulse for the case of perfect heat transfer. For the conditions chosen, lithium and LiF thermal blocks show almost identical peak values of effective specific impulse, with the peak for lithium occurring at a slightly higher value of total mass flow, indicating a higher mass of nitrogen and a lower mass of thermal block compared to LiF for the same total impulse. The beryllium thermal mass showed about $10 \%$ lower effective specific impulse.

For the detailed analysis, we chose the Li thermal block material for several reasons.

1. The maximum performance for the $\mathrm{Li}$ thermal mass is at a higher value of nitrogen mass and a lower value of the thermal block mass. Since the nitrogen mass is acquired on the surface, this means a lower landed mass of the vehicle. 
2. After the phase change, the thermal conductivity of the solidified LiF salt is significantly reduced. This reduction in thermal conductivity may reduce the effectiveness of heat transfer from the thermal mass to the gas. Lithium, on the other hand, as a liquid metal, retains high thermal conductivity through the full range of operation.

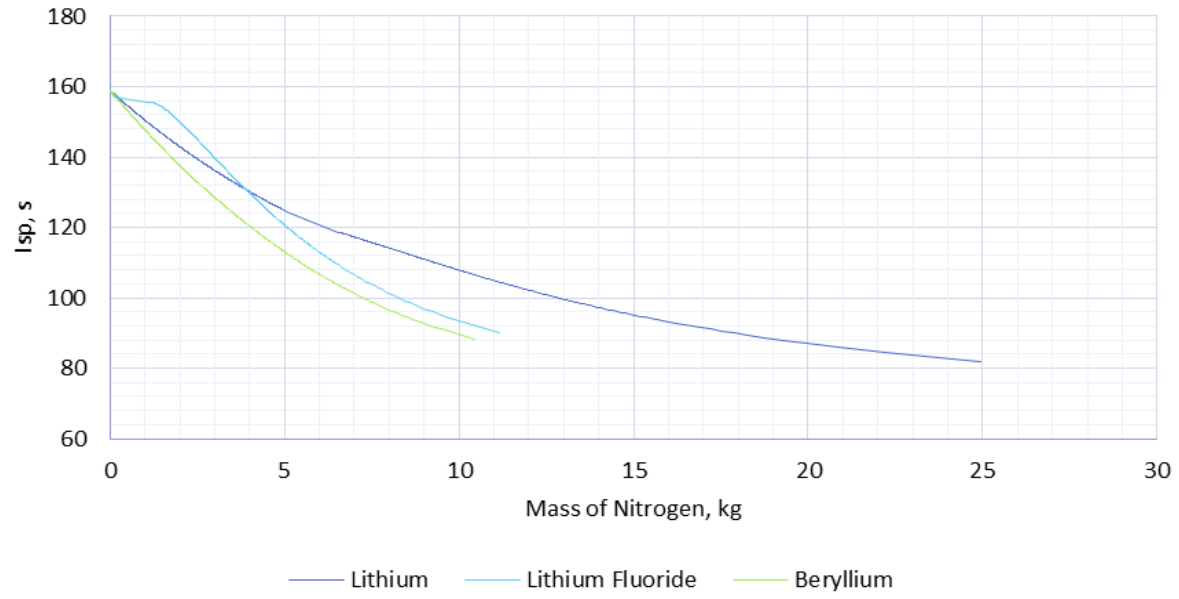

Figure 4. Average specific impulse. The plot shows the average $I_{s p}$ generated by the engine as a function of the total amount of nitrogen flow through the thermal mass, for the different thermal block materials proposed, with a $1-\mathrm{kg}$ thermal block at an initial temperature set at $900^{\circ} \mathrm{C}$. The specific impulse decreases as more nitrogen is run through the system because of the decreased thermal block temperature.

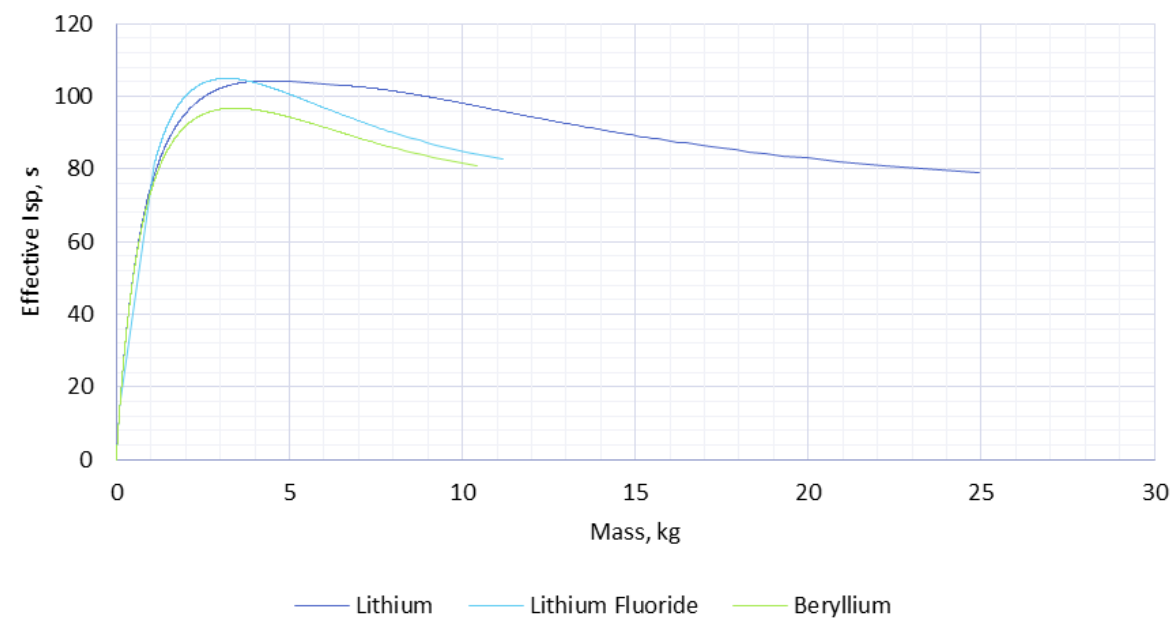

Figure 5. Effective specific impulse as a function of amount of nitrogen flow through the thermal mass. Effective specific impulse is defined as impulse produced per mass of both propellant and thermal storage.

\section{Heat Transfer Analysis}

The system proposed consists of a thermal block which acts as a heat exchanger with passages through which the propellant flows. As the propellant flows through the passages, it heats up to a temperature close to $900^{\circ} \mathrm{C}$ before exiting through the nozzle. A preliminary heat transfer analysis was performed to determine if the heat reservoir system would produce the heat transfer rate needed to achieve the $900^{\circ} \mathrm{C}$ exit temperature of the propellant. The system was analyzed as heat transfer through a tube with constant surface temperature. It was assumed that the temperature 
of the reservoir material remains constant throughout the process, thus providing the constant surface temperature condition. In addition, heat transfer through conduction was ignored. The values of the properties of the propellant are for nitrogen at atmospheric pressure. For preliminary analysis purposes it is assumed that these properties do not change with pressure.

\section{A. Heat transfer analysis theory}

For a flow inside a tube which has constant surface temperature, the heat transfer to or from the fluid is given by Newton's law of cooling.

$$
\dot{Q}=h A_{s} \Delta T_{a v g}=h A_{s}\left(T_{S}-T_{m}\right)_{a v g}
$$

where $\mathrm{h}$ is the convective heat transfer coefficient in $\mathrm{W} / \mathrm{m}^{2}{ }^{0} \mathrm{C}, \mathrm{A}_{\mathrm{s}}$ is the heat transfer surface area of the tube which is equal to $\pi \mathrm{DL}\left(\mathrm{m}^{2}\right)$, and $\Delta \mathrm{T}_{\mathrm{avg}}$ is the average temperature difference between the fluid and the surface of the tube.

The log mean temperature was used as the average temperature difference. The log mean temperature is an exact representation of the average temperature difference between the fluid and the surface temperature, which is why it is used to determine the properties of the fluid and to calculate the heat transfer rate (from Çengel \& Ghajar $2015^{16}$ ).

$$
\Delta T_{l m}=\frac{T_{i}-T_{e}}{\ln \left[\left(T_{s}-T_{e}\right) /\left(T_{s}-T_{i}\right)\right]}
$$

where $T_{i}$ is the initial temperature of the fluid at the tube entry, $T_{s}$ is the surface temperature of the tube, and $T_{e}$ is the exit temperature of the fluid at the tube exit.

The convective heat transfer coefficient depends on whether the fluid flow is laminar or turbulent. This is determined from the Reynolds number. For flow inside a tube, a Reynolds number smaller than 2,300 means that the fluid is laminar, while a number larger than 4,000 means the flow is fully turbulent. Any number in between 2,300 and 4,000 means the fluid is in its transition state between laminar and turbulent. The Reynolds number is defined by the following function:

$$
R e=\frac{\rho V_{a v g} D}{\mu}=\frac{4 \dot{m}}{\mu \pi D}
$$

where $\mu$ is the viscosity of nitrogen at the mean $\log$ temperature, and D is the diameter of the tube. The density of nitrogen $(\rho)$ is calculated by dividing the mass of gas being stored by the volume of the $\operatorname{tank}\left(\mathrm{kg} / \mathrm{m}^{3}\right)$.

The heat transfer coefficient can be determined from the Nusselt number $(\mathrm{Nu})$ which is defined as:

$$
N u=\frac{h D}{k}
$$

where $\mathrm{h}$ is the convective heat transfer coefficient, $\mathrm{D}$ is the diameter of the tube $(\mathrm{m})$, and $\mathrm{k}$ is the heat conduction coefficient of the fluid $\left(\mathrm{W} / \mathrm{m}^{0} \mathrm{C}\right)$. For laminar fluid flow in a tube of constant surface temperature, the Nusselt number has a value of 3.66. For turbulent flow, the Nusselt number is a function of the Reynolds number (Re) and the Prandtl number (Pr), and is defined as:

$$
N u=0.023 \operatorname{Re}^{0.8} \operatorname{Pr}^{n}
$$

where $\mathrm{n}$ is 0.4 for heating and 0.3 for cooling of the fluid.

For turbulent flow, the Nusselt number is given by the Gnielinski equation:

$$
N u=\frac{(f / 8)(R e-1000) \operatorname{Pr}}{1+12.7(f / 8)^{\frac{1}{2}}\left(\operatorname{Pr}^{\frac{2}{3}}-1\right)}
$$

The Prandtl number is defined as:

$$
\operatorname{Pr}=\frac{\mu C_{p}}{k}
$$

where $\mu$ is the viscosity in $\mathrm{kg} / \mathrm{m}-\mathrm{s}, C_{p}$ is the heat capacity $\left(\mathrm{kJ} / \mathrm{kg}^{\circ} \mathrm{C}\right)$, and $\mathrm{k}$ is the thermal conductivity of nitrogen at the mean log temperature $\left(\mathrm{W} / \mathrm{m}^{\circ} \mathrm{C}\right)^{17}$. 
The average velocity of the fluid is determined from the mass flow rate of nitrogen.

$$
V_{\text {avg }}=\dot{m} / \rho A_{c}
$$

where Ac is the cross sectional area of the tube $\left(\mathrm{m}^{2}\right)$. The case being analyzed is for 1 tube of the thermal block, thus the mass flow rate used in the analysis is the mass flow rate of Nitrogen entering the thermal block, divided by the amount of passages in it.

The temperature of the propellant at the exit of the tube is given by equation 17 for flow through a tube with constant surface temperature.

$$
T_{e}=T_{s}-\left(T_{s}-T_{i}\right) \exp \left(-\frac{h A_{s}}{\dot{m} C_{p}}\right)
$$

The temperature difference between the surface of the fluid decays exponentially as the magnitude of the exponent increases. The value of the exponent is known as the number of transfer units, denoted by NTU. The unitless number NTU is a measure of the effectiveness of the heat transfer system. An NTU value of 5 or higher means the heat transfer rate has reached a maximum and assures that the exit temperature of the fluid will be almost equal to the surface temperature of the tube. A value of less than 5 means the heat transfer can be improved by extending the length of the passage.

\section{B. Pressure loss theory}

The pressure loss at the exit of the tube is given by equation 18 . Here $\rho \mathrm{V}_{\text {avg }}{ }^{2} / 2$ is the dynamic pressure and $f$ is the Darcy friction factor. The $\left(\frac{T_{i}+T_{o}}{2 T_{i}}\right)$ factor in the equation accounts for the fact that compressible fluids expand due to the pressure drop.

$$
\Delta P_{L}=f \frac{L}{D}\left(\frac{\rho V_{a v g}^{2}}{2}\right)\left(\frac{T_{i}+T_{o}}{2 T_{i}}\right)
$$

The value of the Darcy friction factor depends on whether the flow is laminar or turbulent. For laminar flow the Darcy friction is given by $f=64 / R e$, whereas for turbulent flow in a smooth tube, the Darcy friction factor is given by $f=(0.790 * \ln (R e)-1.64)^{2}$.

\section{Heat transfer analysis for a lithium thermal block}

A specific case was studied for a heat reservoir composed of 1000 tubes of 1 millimeter diameter and 20 centimeters in length. The heat transfer analysis was performed for 1 of the 1000 tubes. A total mass of 35 kilograms of nitrogen was assumed to be stored in a spherical tank at a pressure of $1000 \mathrm{psi}(6894.7 \mathrm{kPa})$. The mass flow rate of nitrogen through the thermal block was assumed to be 100 grams per second. The temperature of the stored nitrogen was assumed to be $-100^{\circ} \mathrm{C}$, and the surface temperature of the tube was assumed to be a constant $900^{\circ} \mathrm{C}$. In order to calculate the mean log temperature, the temperature at the exit of the tube was assumed to be $899^{\circ} \mathrm{C}$, meaning that the fluid reaches the temperature of the surface of the tube. All the properties of nitrogen were evaluated at the mean $\log$ temperature given by equation 10 .

$$
\Delta T_{l m}=\frac{T_{i}-T_{e}}{\ln \left[\left(T_{s}-T_{e}\right) /\left(T_{s}-T_{i}\right)\right]}=\frac{-100-900}{\ln [(900-899) /(900+100)]}=145^{\circ} \mathrm{C}
$$

The heat capacity, viscosity, and heat conductivity of nitrogen at $145^{\circ} \mathrm{C}$ are ${ }^{17}$ :

$$
\begin{aligned}
& C_{p}=1.0458 \frac{\mathrm{kJ}}{\mathrm{kg}^{\circ} \mathrm{C}} \\
& \mu=2.267 \times 10^{-5} \frac{\mathrm{kg}}{\mathrm{ms}} \\
& k=0.0339 \frac{\mathrm{W}}{\mathrm{m}^{\circ} \mathrm{C}}
\end{aligned}
$$


The density of nitrogen was determined from the assumption that $35 \mathrm{~kg}$ are being stored in a spherical tank at a pressure of $1000 \mathrm{psi}(6894.7 \mathrm{kPa})$. The volume of the tank is determined from the ideal gas law.

$$
\begin{gathered}
P V=n R T \rightarrow V=\frac{n R T}{P}=\left(\frac{35 \mathrm{~kg}}{0.028 \frac{\mathrm{kg}}{\mathrm{mol}}}\right) *\left(8.3145 \frac{\mathrm{J}}{\mathrm{Kmol}}\right) *\left(\frac{173 \mathrm{~K}}{6.895 * 10^{6} \mathrm{~Pa}}\right)=0.261 \mathrm{~m}^{3} \\
\rho=\frac{m}{V}=134.3 \frac{\mathrm{kg}}{\mathrm{m}^{3}}
\end{gathered}
$$

The mass flow rate per tube of the heat reservoir is determined by dividing the total flow rate by the amount of passages, and the average fluid velocity is determined from equations 16.

$$
\begin{gathered}
\dot{m}=\frac{\left(0.1 \frac{\mathrm{kg}}{\mathrm{s}}\right)}{1000}=0.0001 \frac{\mathrm{kg}}{\mathrm{s}} \\
A_{c}=\frac{\pi}{4} D^{2}=\frac{\pi}{4} *(0.001 \mathrm{~m})^{2}=7.85 \times 10^{-7} \mathrm{~m}^{2} \\
V_{\text {avg }}=\frac{\dot{m}}{\rho A_{c}}=\frac{0.0001 \frac{\mathrm{kg}}{\mathrm{s}}}{134.3 \frac{\mathrm{kg}}{\mathrm{m}^{3}} * 7.85 \times 10^{-7} \mathrm{~m}^{2}}=0.95 \frac{\mathrm{m}}{\mathrm{s}}
\end{gathered}
$$

The Reynolds number is calculated from:

$$
R e=\frac{\rho V_{a v g} D}{\mu}=\frac{\left(134.3 \frac{\mathrm{kg}}{\mathrm{m}^{3}}\right)\left(0.95 \frac{\mathrm{m}}{\mathrm{s}}\right)(0.001 \mathrm{~m})}{\left(2.267 \times 10^{-5} \frac{\mathrm{kg}}{\mathrm{ms}}\right)}=5615.67
$$

In our case, $\operatorname{Re}>4000$, and thus the fluid flow is fully turbulent. Knowing that the flow inside the tube is fully turbulent, the Prandtl, Nusselt number, and convective heat transfer coefficient are calculated from equations 15,14 and 12 , respectively.

$$
\begin{gathered}
\operatorname{Pr}=\frac{\mu C_{p}}{k}=\frac{\left(2.267 \times 10^{-5} \frac{\mathrm{kg}}{\mathrm{ms}}\right)\left(1.0458 \frac{\mathrm{KJ}}{\mathrm{kg}^{\circ} \mathrm{C}}\right)}{0.0339 \frac{\mathrm{W}}{\mathrm{m}^{\circ} \mathrm{C}}}=0.70 \\
N u=\frac{(f / 8)(R e-1000) \operatorname{Pr}}{1+12.7(f / 8)^{\frac{1}{2}}\left(\operatorname{Pr}^{\frac{2}{3}}-1\right)}=\frac{(0.037 / 8)(5615.67-1000) * 0.70}{1+12.7(0.037 / 8)^{1 / 2}\left(0.70 \frac{2}{3}-1\right)}=18.42 \\
N u=\frac{h D}{k} \rightarrow h=\frac{N u k}{D}=\frac{\left(18.42 * 0.0339 \frac{\mathrm{W}}{\mathrm{m}^{\circ} \mathrm{C}}\right)}{0.001 \mathrm{~m}}=625 \frac{\mathrm{W}}{\mathrm{m}^{2 \circ} \mathrm{C}}
\end{gathered}
$$

The number of transfer units is determined as follows;

$$
A_{s}=\pi D L=\pi(0.001 m)(0.2 m)=0.0006283 m^{2}
$$




$$
N T U=\frac{h A_{s}}{\dot{m} C_{p}}=\frac{\left(625 \frac{\mathrm{W}}{\mathrm{m}^{2 \circ} \mathrm{C}}\right)\left(0.0006283 \mathrm{~m}^{2}\right)}{0.0001 \frac{\mathrm{kg}}{\mathrm{S}} * 1.0458 \frac{\mathrm{KJ}}{\mathrm{kg}^{\circ} \mathrm{C}}}=3.75
$$

The NTU value is close to 5 which indicates that the temperature of the fluid at the exit will be close to the surface temperature of the tube (from Çengel \& Ghajar $2015^{16}$ ). Using the equation for the exit temperature and substituting the values for the variables yields:

$$
\begin{aligned}
& T_{e}=T_{s}-\left(T_{s}-T_{i}\right) \exp \left(-\frac{h A_{s}}{\dot{m} C_{p}}\right)=900^{\circ} \mathrm{C}-\left(900^{\circ} \mathrm{C}+100^{\circ} \mathrm{C}\right) \exp (-3.75) \\
& T_{e}=877^{\circ} \mathrm{C}
\end{aligned}
$$

As expected, the exit temperature at the exit is close to the surface temperature of the tube $\left(900^{\circ} \mathrm{C}\right)$.

The heat transfer rate to the fluid is defined as:

$$
\dot{Q}=h A_{s} \Delta T_{l m}=\left(625 \frac{W}{m^{2 \circ} \mathrm{C}}\right)\left(0.0006283 \mathrm{~m}^{2}\right)\left(145^{\circ} \mathrm{C}\right)=57 W
$$

\section{Pressure drop}

The pressure drop through the tube must be less than the pressure of the gas in the tank pressure, or else the flow rate will not be achievable.

Finally, the pressure drop throughout the tube is determined from the pressure loss equation using the Darcy friction factor for turbulent flow inside a smooth tube.

$$
\begin{gathered}
f=(0.790 \ln R e-1.64)^{-2}=(0.790 \ln (5615.67)-1.64)^{-2}=0.037 \\
\Delta P_{L}=f \frac{L}{D}\left(\frac{\rho V_{\text {avg }}^{2}}{2}\right)\left(\frac{T_{i}+T_{o}}{2 T_{i}}\right)=\quad(0.037)\left(\frac{0.2 \mathrm{~m}}{0.001 \mathrm{~m}}\right)\left(\frac{134.3 \frac{\mathrm{kg}}{\mathrm{m}^{3}} *\left(0.95 \frac{\mathrm{m}}{\mathrm{s}}\right)^{2}}{2}\right)\left(\frac{-100+899}{2 *-100}\right)=1747 P a
\end{gathered}
$$

The calculation shows that the requirement that the pressure drop through the tube be less than the tank pressure is reasonable, since the anticipated tank pressures are many MPa.

\section{Heat Transfer Analysis}

\section{A. Fluid temperature gradient}

Numerical integration was used to determine the temperature gradient of the fluid along the tube. The fluid exit temperature was analyzed at $1 \mathrm{~mm}$ length increments of the tube. The surface area and NTU value of each section mas calculated, and the surface temperature of the fluid was determined from equation 17.

where the NTU is defined as $-\frac{h A_{s}}{\dot{m} C_{p}}$.

$$
T_{e}=T_{s}-\left(T_{s}-T_{i}\right) \exp \left(-\frac{h A_{s}}{\dot{m} C_{p}}\right)
$$

The results, shown in figure 6 , obtained are consistent with the ones obtained from the previous analysis. The exit temperature of the fluid at the end of the passage is $877^{\circ} \mathrm{C}$. To obtain an exit temperature higher than this would require longer passages. An increase in length of the tubes results in an increase in the NTU number. Once the NTU reaches a value of 5, the heat transfer has reached its limit and the exit temperature will not increase with any further increase in tube length. 


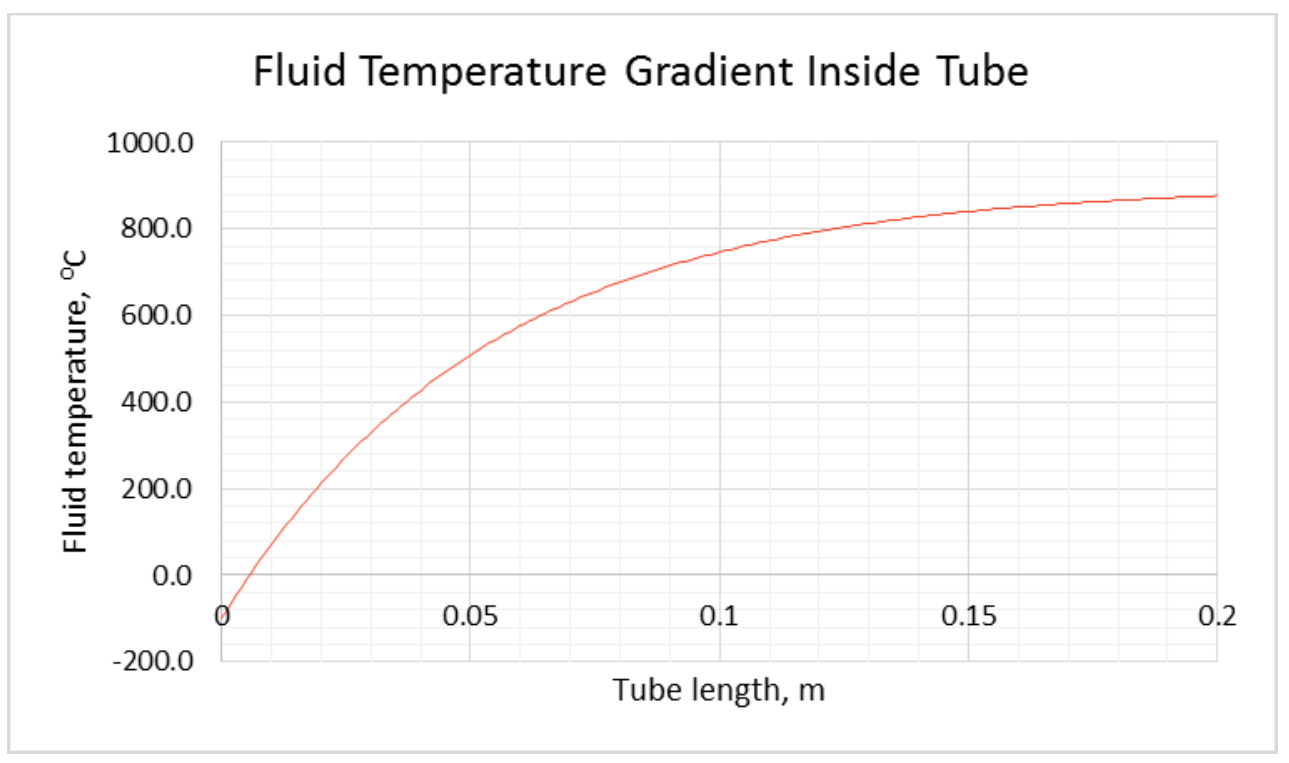

Figure 6. Fluid temperature gradient. Plot shows the temperature gradient of the fluid along the tube which has a constant surface temperature of $900^{\circ} \mathrm{C}$. The fluid enters the thermal block at $-100^{\circ} \mathrm{C}$ and exits at $877^{\circ} \mathrm{C}$.

The amount of heat added to the fluid with each increment of temperature is determined from equation 19.

$$
\Delta \dot{Q}=\dot{m} C_{p} \Delta T=\dot{m} C_{p}\left(T_{e}-T_{i}\right)
$$

where $\dot{m}$ the mass flow rate per tube, $C_{p}$ is the heat capacity of nitrogen at the mean logarithmic temperature and $\Delta \mathrm{T}$ is the temperature change of the fluid between the entry and the exit of the $1 \mathrm{~mm}$ section being analyzed. The analysis indicates that a total of $102 \mathrm{~W}$ need to be added to the fluid for it to reach an exit temperature of $877^{\circ} \mathrm{C}$.

\section{B. Thermal mass tube surface temperature gradient.}

The surface temperature gradient along the tube was analyzed for a thermal mass made out of lithium. Numerical integration with $1 \mathrm{~mm}$ tube length increments was used to determine the surface temperature gradient along the tube. The amount of thermal mass per section of tube length was determined from equation 20.

$$
\Delta m=\frac{m_{t h} \Delta x}{L * 1000}=\frac{1 \mathrm{~kg} * 0.001 \mathrm{~m}}{0.2 \mathrm{~m} * 1000}=0.000005 \mathrm{~kg}=5 \mu \mathrm{g}
$$

Thus, each $1 \mathrm{~mm}$ section of tube is surrounded by $5 \mu \mathrm{g}$ of lithium.

The rate of temperature change of the surface of the tube is determined from equation 21.

$$
\frac{d T}{d t}=\frac{\Delta \dot{Q}}{\Delta m C_{p}}
$$

where $\Delta \dot{Q}$ is the heat added to the $1 \mathrm{~mm}$ section of tube, $\Delta \mathrm{m}$ is the amount of lithium surrounding the section of tube, and $C_{p}$ is the heat capacity of lithium, evaluated at the temperature of the fluid. 


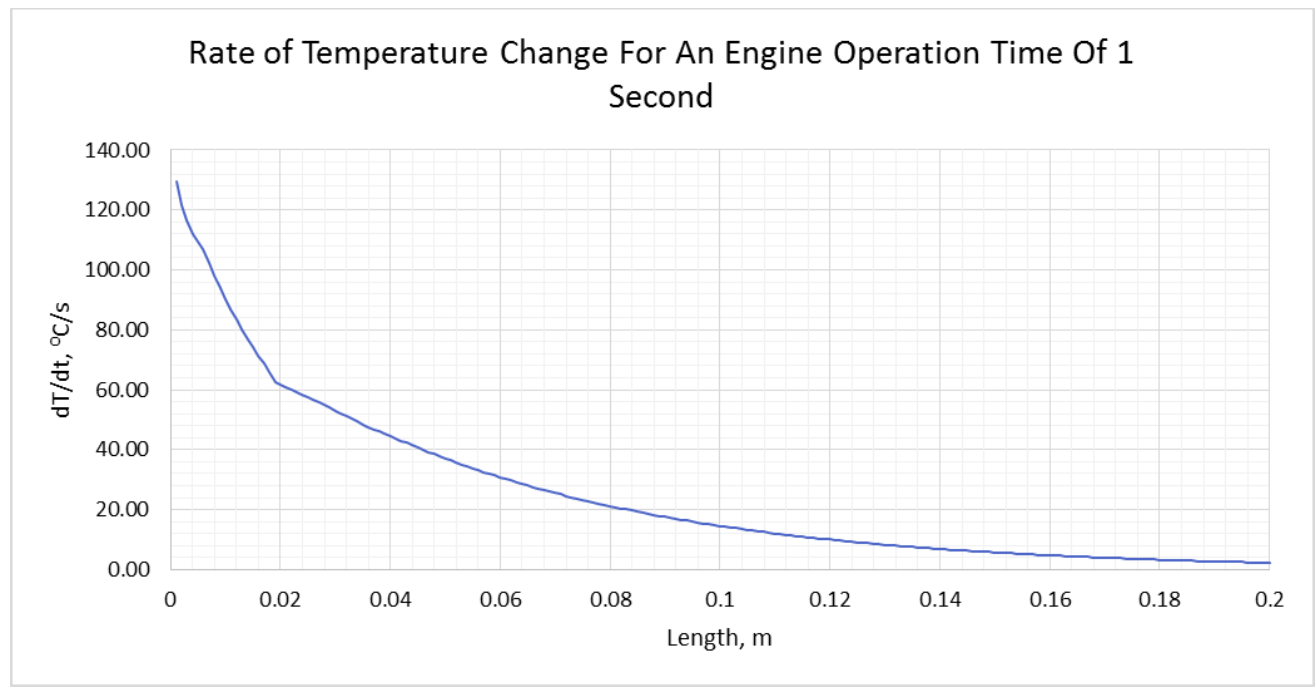

Figure 7. Rate of temperature for an engine operation time of 1 second. The plot shows the rate at which the temperature of the surface of the tube decreases for an engine operation time of 1 second.

The surface temperature of the tube is determined by subtracting the temperature change resulting from 1 second of engine operation, from the initial surface temperature of the tube.

$$
T_{s f}=T_{s 0}-t * \frac{d T}{d t}
$$

This is shown in figure 7. During the first second of engine operation, the surface temperature of the entry region of the passage drops to $770^{\circ} \mathrm{C}$.

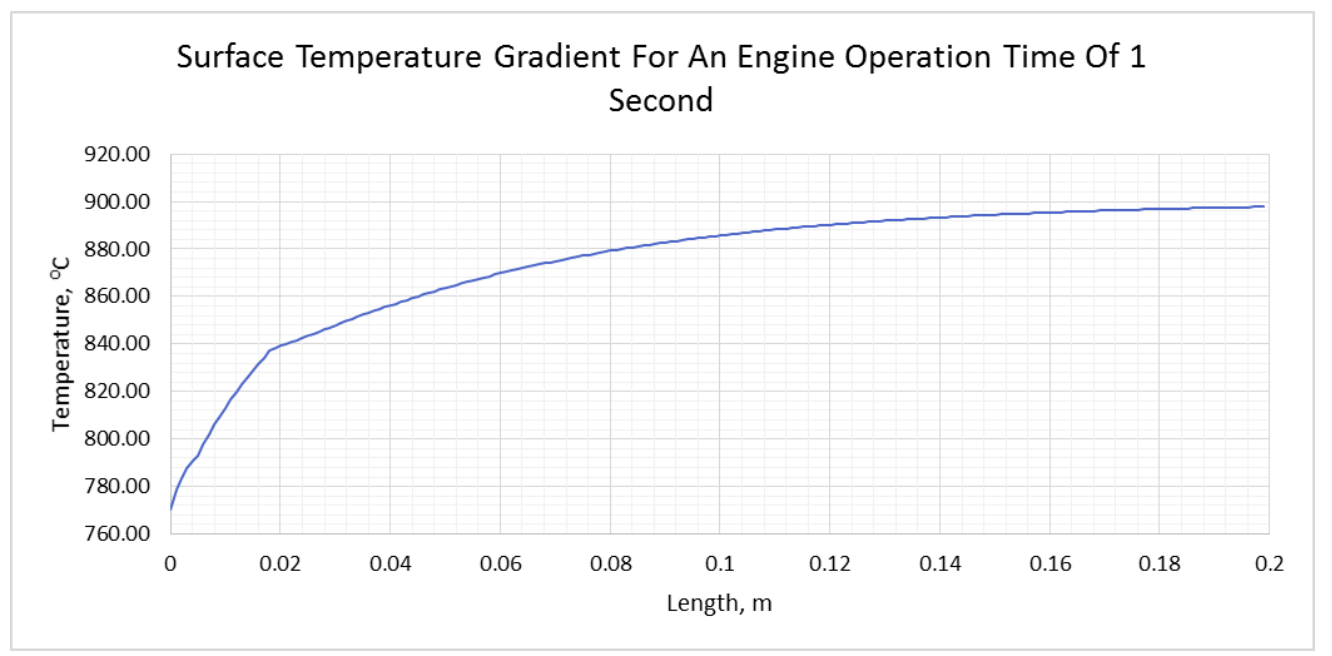

Figure 8. Surface temperature gradient for an engine operation time of 1 second. The plot shows the change in temperature of the surface of the tube throughout its length for 1 second of engine operation time.

The temperature of the surface of the tube is changing with time, and thus the amount of heat entering the fluid is changing with time as the thermal mass is cooling down. This means that the rate of temperature change of the surface, the fluid temperature, and the heat transfer, all need to be recalculated for each second of operation. The results for an engine operation time of 50 seconds are presented in figure 9. 


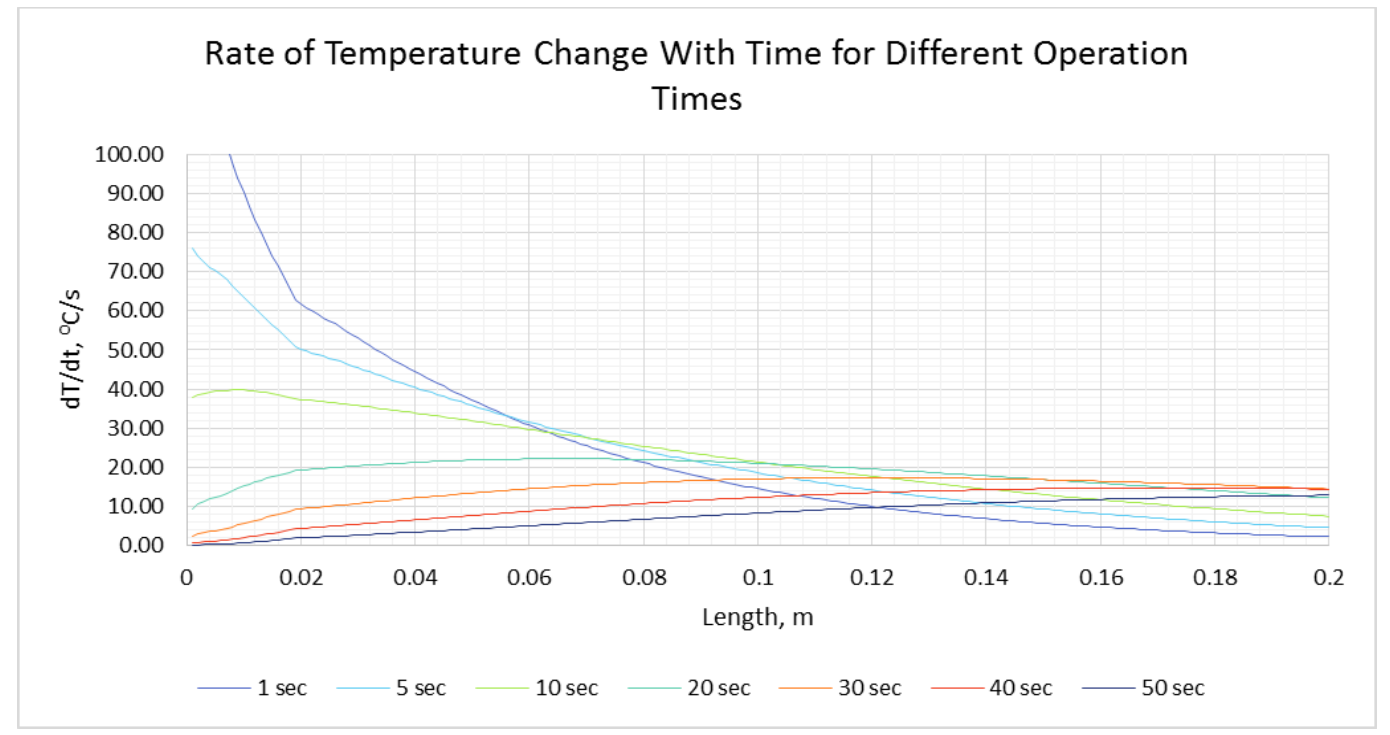

Figure 9. Rate of surface temperature change for various engine operation times.

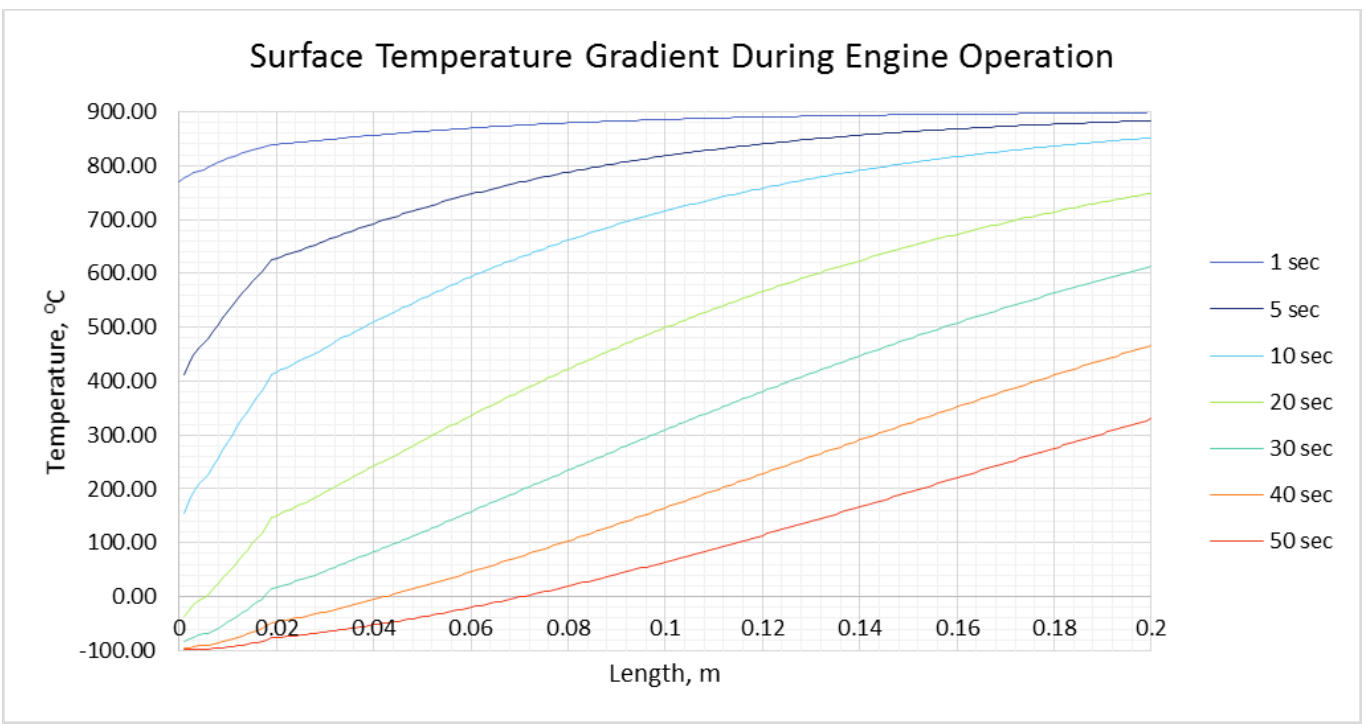

Figure 10. Surface temperature gradient during various engine operation times. In this plot, cold gas $\left(\mathrm{T}_{\mathrm{i}}=\right.$ $100^{\circ} \mathrm{C}$ ) enters from the left at $\mathrm{x}=0$, and flows to the right. Initial temperature is $900^{\circ} \mathrm{C}$, and mass flow rate is 0.1 $\mathrm{kg} / \mathrm{sec}$.

\section{Corrected Specific Impulse}

Once the temperature gradient across the tube length is known, the average and effective specific impulse are recalculated to incorporate the calculated details of how the change in temperature of the thermal block affects the performance of the engine. Since the thermal mass is cooling down as nitrogen passes through it, the performance of the engine will decrease with time. To determine the performance of the engine as a function of engine operation time, the fluid temperature at the exit is calculated for 50 seconds of engine operation. This is done by calculating the fluid 
temperature at the exit of the passages for 1 second time increments. The change in fluid exit temperature as a function of time is shown in figure 11 .

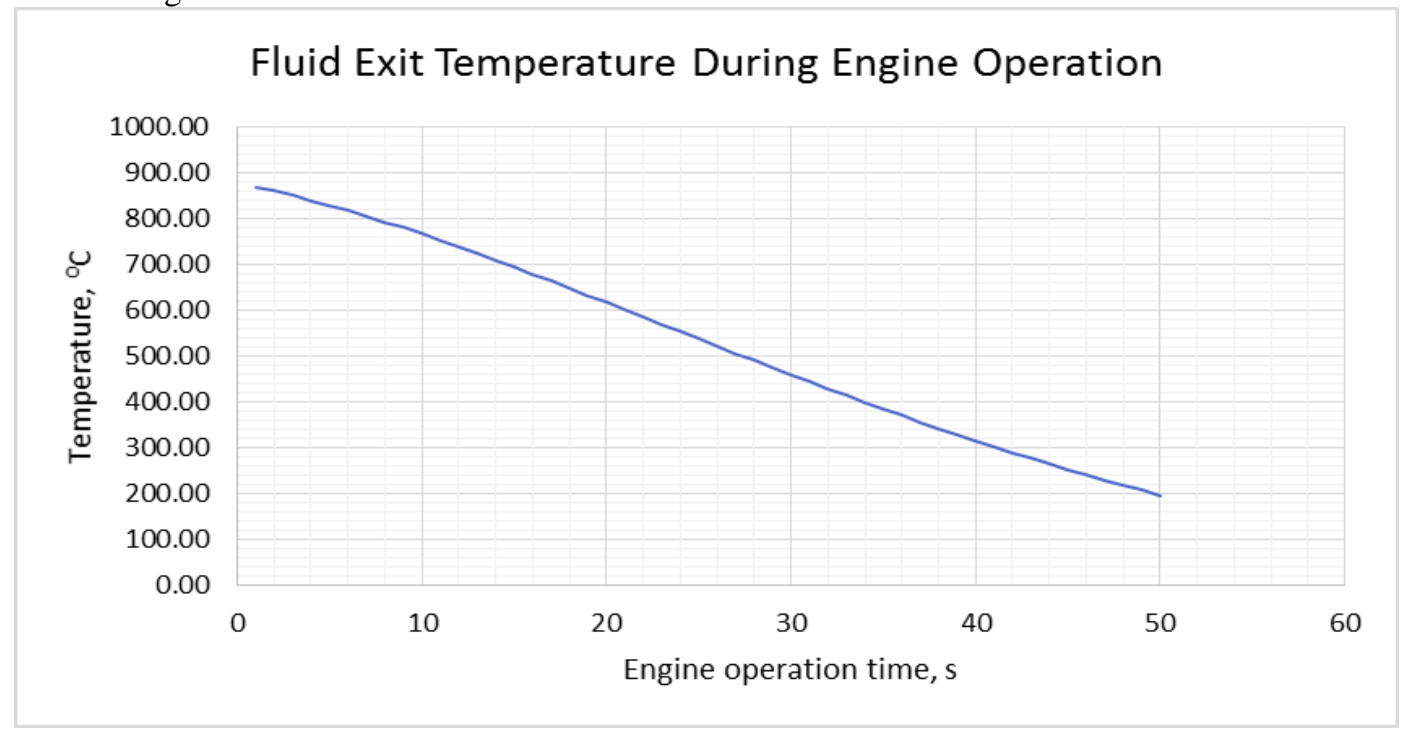

Figure 11. Propellant exit temperature as a function of engine operation time (mass flow rate $0.1 \mathrm{~kg} / \mathrm{sec}$ ).

Next, the exhaust velocity is recalculated with the new values for fluid exit temperature. In the initial calculations for specific impulse, the $\Delta \mathrm{m}$ of nitrogen determined represented the amount of nitrogen needed to reduce the temperature of $1 \mathrm{~kg}$ thermal mass by $1^{\circ} \mathrm{C}$. Assuming that the temperature gradient of the thermal mass is equal to the temperature gradient of the surface of the tube, and using a $\Delta \mathrm{m}$ of $0.1 \mathrm{~kg}$, which corresponds to the mass flow rate of $0.1 \mathrm{~kg} / \mathrm{s}$ used in the heat transfer analysis, the performance of the engine can be determined for any desired engine operation time. With the exhaust velocity and the $\Delta \mathrm{m}$ determined, the impulse can be calculated from $I=V_{e} * \Delta m$. The plot for the average and effective specific impulse is presented in figure 12. The maximum average specific impulse generated is $157 \mathrm{~s}$, while the maximum effective specific impulse reached is $109 \mathrm{~s}$.

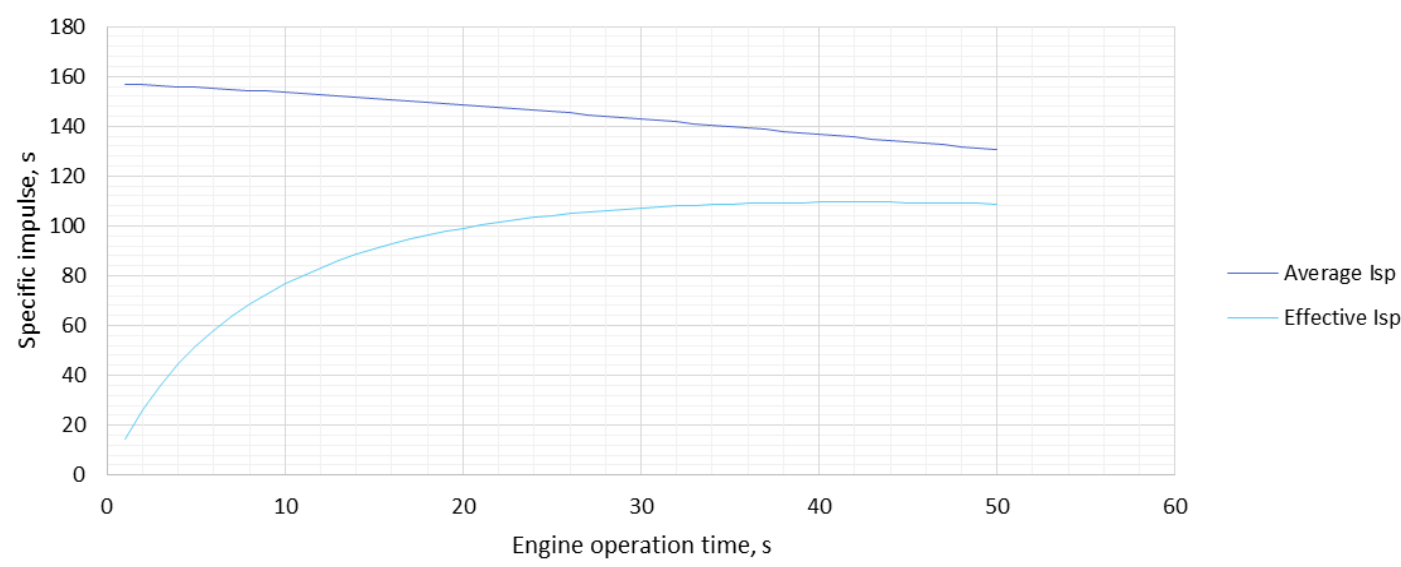

Figure 12. Engine performance as a function of engine operation time (mass flow rate $0.1 \mathrm{~kg} / \mathrm{sec}$ ). 


\section{Tank Parametrics}

\section{A. Tank sizing}

The Triton Hopper will use a spherical tank to store the nitrogen collected. The tank is assumed to be a Compositeoverwrapped pressure vessel (COPV) ${ }^{19}$ tank having a minimum thickness of 0.125 in and constructed out of carbon fiber fabric which has a density of $1600 \mathrm{~kg} / \mathrm{m}^{3}$ and an ultimate tensile strength of $600 \mathrm{MPa}$. The values for the density and ultimate tensile strength of the carbon fiber fabric were obtained from ACP composites.

The volume of the tank depends on the amount of nitrogen being stored, and the temperature and pressure at which it is being stored. Taking one of these parameters as a constant, allows for the determination of the tank's radius as a function of the other two parameters. Thus, by taking the mass of nitrogen as a constant $35 \mathrm{~kg}$, the tank's size can be determined as a function of temperature and pressure.

The inner volume of the tank is determined from the ideal gas law. Choosing a factor of safety of 1.5 for the design, the maximum allowable stress is determined to be $400 \mathrm{MPa}$. The thickness of the tank walls is determined from the hoop stress equation by solving for the thickness.

$$
\sigma_{\text {hoop }}=S F * \frac{P D_{\text {mean }}}{4 t h}
$$

where SF is the safety factor chosen, $\mathrm{P}$ is the pressure inside the tank $(\mathrm{Pa})$, th is the thickness of the tank $(\mathrm{m})$, and $\mathrm{D}_{\text {mean }}$ is the mean diameter of the tank (inner diameter plus the thickness). A plot of the size of the tank as a function of temperature, nitrogen mass and pressure is obtained by repeating these calculations for different values of mass, pressure and temperature. Figure 13 shows this calculation for a propellant mass of $35 \mathrm{~kg}$. As expected, higher pressures allow considerably smaller tank diameter.

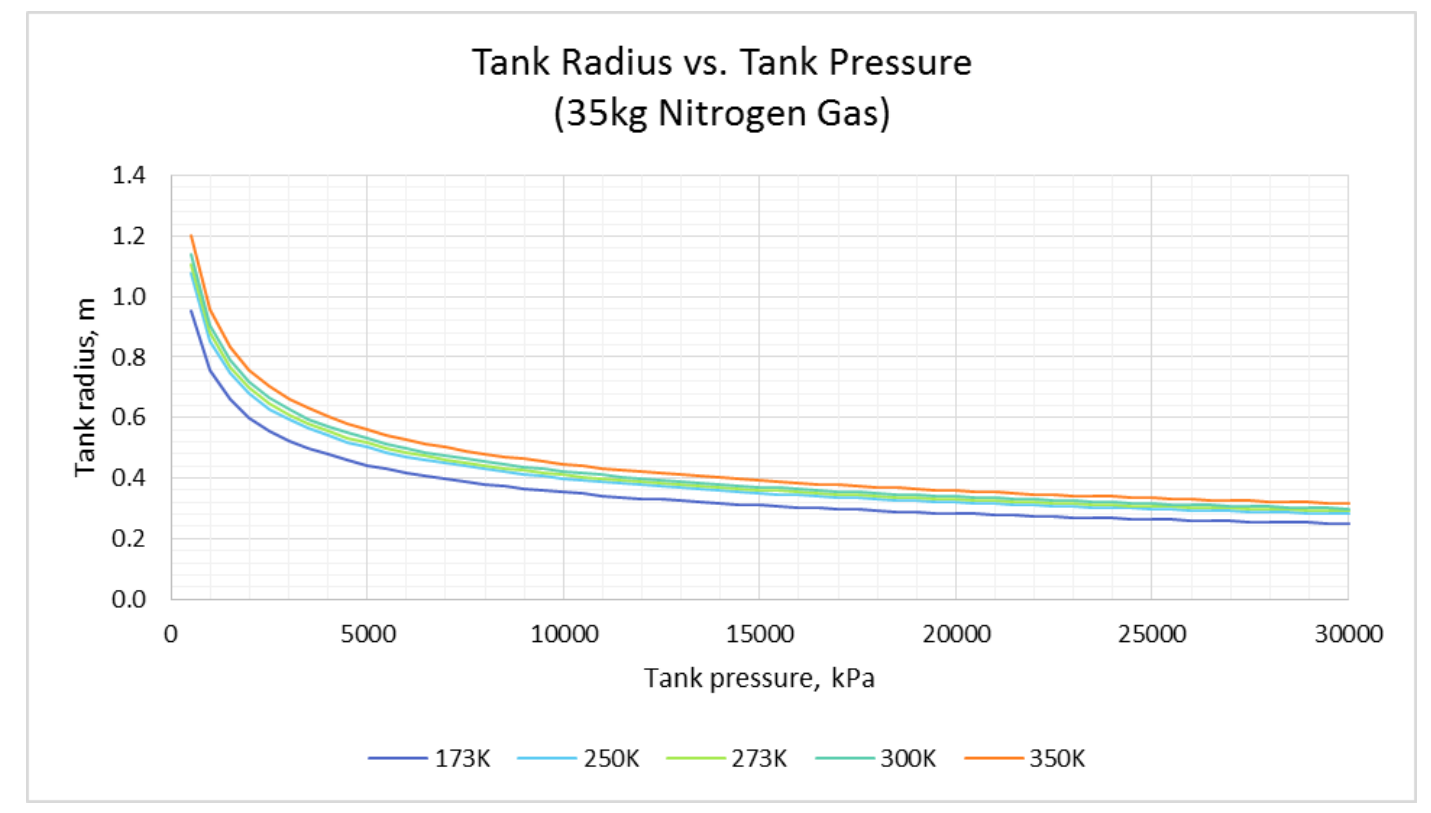

Figure 1. Tank radius as a function of pressure and temperature for propellant mass of $35 \mathrm{~kg}$.

The mass of the tank, $\mathrm{M}$, is determined from equation 23, where $\mathrm{P}$ is the tank's pressure, $\mathrm{V}$ is the tank's volume, $\sigma$ is the ultimate tensile strength of the material, and $\rho$ is the density of the material.

$$
M=\frac{3}{2} P V \frac{\sigma}{\rho}
$$

Figure 14 shows the tank mass as a function of tank pressure and initial nitrogen temperature, again for the Triton hopper case of $35 \mathrm{~kg}$ of propellant. As can be seen, the mass of the tank increases with the storage temperature, but is 
nearly independent of the pressure. This is because although the tank volume at higher pressure is smaller, the wall thickness required is proportionally higher, with the two factors cancelling out.

This graph shows the main reason for the choice of an initial gas temperature of $173 \mathrm{~K}(-100 \mathrm{C})$ which was used in the calculations in the previous section: the low gas temperature minimizes the tank mass. (A secondary consideration is that low temperatures minimize the insulation needed to reduce the heat loss to the ambient, as discussed in the next section).

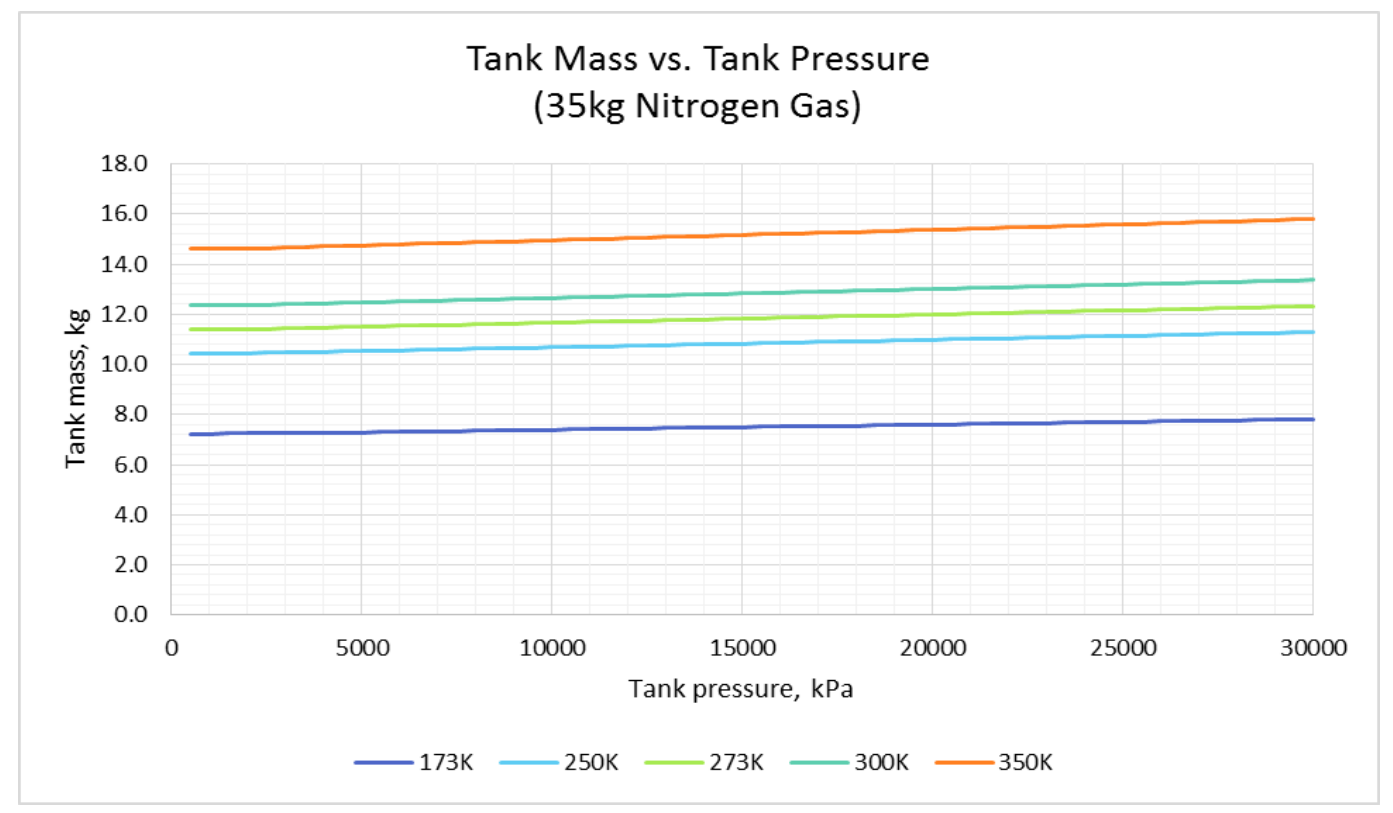

Figure 2. Tank mass as a function of pressure and temperature.

\section{B. Tank insulation}

The amount of heat that the system loses to its surroundings needs to be calculated in order to determine the amount of heat required to store the gas at the desired temperature and to heat the thermal block to $900^{\circ} \mathrm{C}$. Multi-Layer Insulation (MLI) will be used to insulate the tank, thermal block, and any other component in the system that causes a high heat loss. The effective heat conductivity of MLI is determined from the effective heat conduction coefficient equation (24).

$$
k_{e f f}=0.625 *\left(1.027 * 10^{-7} *\left(\frac{T_{H}+T_{C}}{2}\right)+3.333 * 10^{-16} *\left(\frac{T_{H}^{4.67}-T_{C}{ }^{4.67}}{T_{H}-T_{C}}\right)\right)
$$

where $T_{H}$ is the temperature of the hot side and $T_{C}$ is the temperature of the cold side in Rankine. The values obtained from this formula have units of $(\mathrm{Btu} / \mathrm{hr}) / \mathrm{ft}-\mathrm{R}$, which are then converted to $\mathrm{SI}(\mathrm{W} / \mathrm{m}-\mathrm{K})$.

The heat lost by the system is determined by solving simultaneously the equations of heat lost due to radiation and conduction. For the case of the nitrogen tank, the equations for heat lost due to conduction and radiation are:

$$
\begin{gathered}
\dot{Q}_{\text {cond }}=k_{\text {eff }} * \frac{A_{s}\left(T_{H}-T_{s}\right)}{t h} \\
\dot{Q}_{r a d}=\varepsilon * \sigma * A_{s} *\left(T_{s}{ }^{4}-T_{s u r}{ }^{4}\right)
\end{gathered}
$$

where $\varepsilon$ is the emissivity of the insulation, $\sigma$ is Boltzmann's constant, $A_{s}$ is the surface area of the tank, $T_{H}$ is the temperature of the nitrogen inside the tank, $\mathrm{T}_{\text {sur }}$ is the temperature of the surroundings, which is $34.5 \mathrm{~K}$ for Triton's 
surface, and $T_{S}$ is the temperature of the outer surface of the insulation. The surface temperature is determined by iterating for the value of $\mathrm{T}_{\mathrm{s}}$ until the heat lost due to conduction is the same as the heat lost due to radiation.

Analyzing the tank's heat loss, we have that the temperature of the hot side is $173 \mathrm{~K}$ while the temperature of the cold side is $34.5 \mathrm{~K}$. From equation 24 , the heat conduction coefficient for the MLI insulation is determined to be $0.0000214 \mathrm{~W} / \mathrm{m}-\mathrm{K}$. Assuming an MLI insulation thickness of $10 \mathrm{~mm}$, the heat conduction and radiation equations are solved simultaneously for the surface temperature, which gives a heat loss of $0.615 \mathrm{~W}$ when the surface temperature is $49.6 \mathrm{~K}$.

This level of heat loss is sufficiently low that it can be provided by the waste heat from the electrical power generation system.

As the tank feeds nitrogen to the thruster, the remaining gas inside the tank expands, and thus the temperature drops due to Joule-Thomson cooling. This reduces the feed pressure. When the tank reaches sufficiently low pressure, the remaining nitrogen in the tank will condense, resulting in some residual fuel remaining in the tank. This problem could be amelierorate, however, if a small fraction of the nitrogen heated by the thermal block is returned to the tank, rather than fed into the nozzle. This would have no effect on the total power requriement, since the thermal energy is still fed into the nitrogen.

\section{Thermal mass insulation}

The amount of heat that the system loses to its surroundings needs to be calculated in order to determine the amount of heat required to store

For the thermal mass, we have that the temperature of the hot side is $1173 \mathrm{~K}$ while the temperature of the cold side is $34.5 \mathrm{~K}$. From equation 24 , the heat conduction coefficient for the MLI insulation is determined to be $0.000711 \mathrm{~W} / \mathrm{m}$ $\mathrm{K}$. Assuming an MLI insulation thickness of $10 \mathrm{~mm}$, the heat conduction and radiation equations are solved simultaneously for the surface temperature, which gives a heat loss of $8.03 \mathrm{~W}$ when the surface temperature is $187 \mathrm{~K}$.

In addition to the heat lost by the tank and the thermal block, heat is lost due to heat leaks such as the tubes that connect the tank, thermal mass and nozzle, which are non-insulated. These heat leaks need to be accounted for in order to determine the amount of heat energy required by the system. The heat lost from the tubes through radiation is equal to the heat conducted from the hot end to the cold end. For the tube connecting the tank and the heated block, the hot end is $900^{\circ} \mathrm{C}$ and the cold end is $-100^{\circ} \mathrm{C}$. Using titanium tubes of $1 \mathrm{~mm}$ in diameter and $20 \mathrm{~cm}$ in length, the heat lost is given by equation 25 .

$$
\begin{aligned}
& \dot{Q}=k * A_{C} * \frac{T_{H}-T_{C}}{L} \\
& =15.9 \frac{W}{m K} * 0.0000817 m^{2} * \frac{1173 K-173 K}{0.2 m}=6.49 \mathrm{~W}
\end{aligned}
$$

The heat loss for the tube connecting the thermal block and the nozzle is greater due to the fact that the nozzle is at ambient temperature.

$$
\begin{aligned}
& \dot{Q}=k * A_{C} * \frac{T_{H}-T_{C}}{L} \\
& =15.9 \frac{\mathrm{W}}{\mathrm{mK}} * 0.0000817 \mathrm{~m}^{2} * \frac{1173 \mathrm{~K}-34.5 \mathrm{~K}}{0.2 \mathrm{~m}}=7.39 \mathrm{~W}
\end{aligned}
$$

The thermocouples used to measure the tank and the thermal block also count as heat leaks. A conservative calculation was done to determine the amount of heat lost if the thermocouples are made of copper wire of $1 \mathrm{~mm}$ and $1 \mathrm{~m}$ length, using values from White and Collocott ${ }^{13}$. The heat lost caused by the thermocouples is calculated from equation 25.

$$
\begin{aligned}
& \dot{Q}_{\text {tank }}=k * A_{C} * \frac{T_{H}-T_{C}}{L} \\
& =385 \frac{W}{m K} * 7.85 * 10^{-7} m^{2} * \frac{173 K-34.5 K}{1 m}=0.04 W
\end{aligned}
$$




$$
\begin{aligned}
& \dot{Q}_{\text {therm_block }}=k * A_{C} * \frac{T_{H}-T_{C}}{L} \\
& =385 \frac{\mathrm{W}}{\mathrm{mK}} * 7.85 * 10^{-7} \mathrm{~m}^{2} * \frac{1173 \mathrm{~K}-34.5 \mathrm{~K}}{1 \mathrm{~m}}=0.34 \mathrm{~W}
\end{aligned}
$$

The results from the conservative analysis show the heat lost due to the thermocouples is negligible.

The total amount of heat lost from the system is $22.26 \mathrm{~W}$.

The mission requirements indicate that the Triton Hopper must hop every 24 days. The power that needs to be provided by the RHUs or GPHS blocks is determined by taking the total amount of heat required to heat the thermal block material from $-100^{\circ} \mathrm{C}$ to $900^{\circ} \mathrm{C}$ and dividing the result by 24 days (in seconds). For the lithium, figure 2 shows that $4.5 \mathrm{~kJ} / \mathrm{kg}$ will heat the block to operating temperature, so the $7 \mathrm{~kg}$ of thermal mass will require $31.5 \mathrm{~kJ}$. Dividing this by the time shows that the average power required to heat the block in 24 days is only $15 \mathrm{~mW}$ greater than the power required to account for the heat leak, and thus the total thermal power required from the radioisitope is $22.3 \mathrm{~W}$.

Knowing the minimum power required to heat the thermal block to $900^{\circ} \mathrm{C}$ allows us to choose the heat source. RHUs provide $1 \mathrm{~W}$ of power per unit, thus, 23 RHUs are enough to keep the thermal block at temperature against the heat loss from the system. Alternately, this can be replaced with a single GPHS block which provides $250 \mathrm{~W}$ per unit.

\section{Lower Operating Temperature Case}

The analysis presented shows the results for an ideal case of where thermal mass reaches a temperature of $900^{\circ} \mathrm{C}$. Realistically, RHUs may not be able to heat the thermal mass to this temperature. The Plutonium radioisotope source would reach a temperature of $1000^{\circ} \mathrm{C}$, but in a more conservative design, the surface of the GPHS block which encapsulates the isotope, would only reach a temperature of $860^{\circ} \mathrm{C}$. For this case, the maximum temperature delivered to the hot side of the thermal mass would be approximately $760^{\circ} \mathrm{C}$. Running the analysis with a thermal mass temperature of $760^{\circ} \mathrm{C}$ is shown in figure 15 . The net result is a specific impulse of $147 \mathrm{~s}$ at the beginning of thrust, and a maximum effective specific impulse of $103 \mathrm{~s}$.

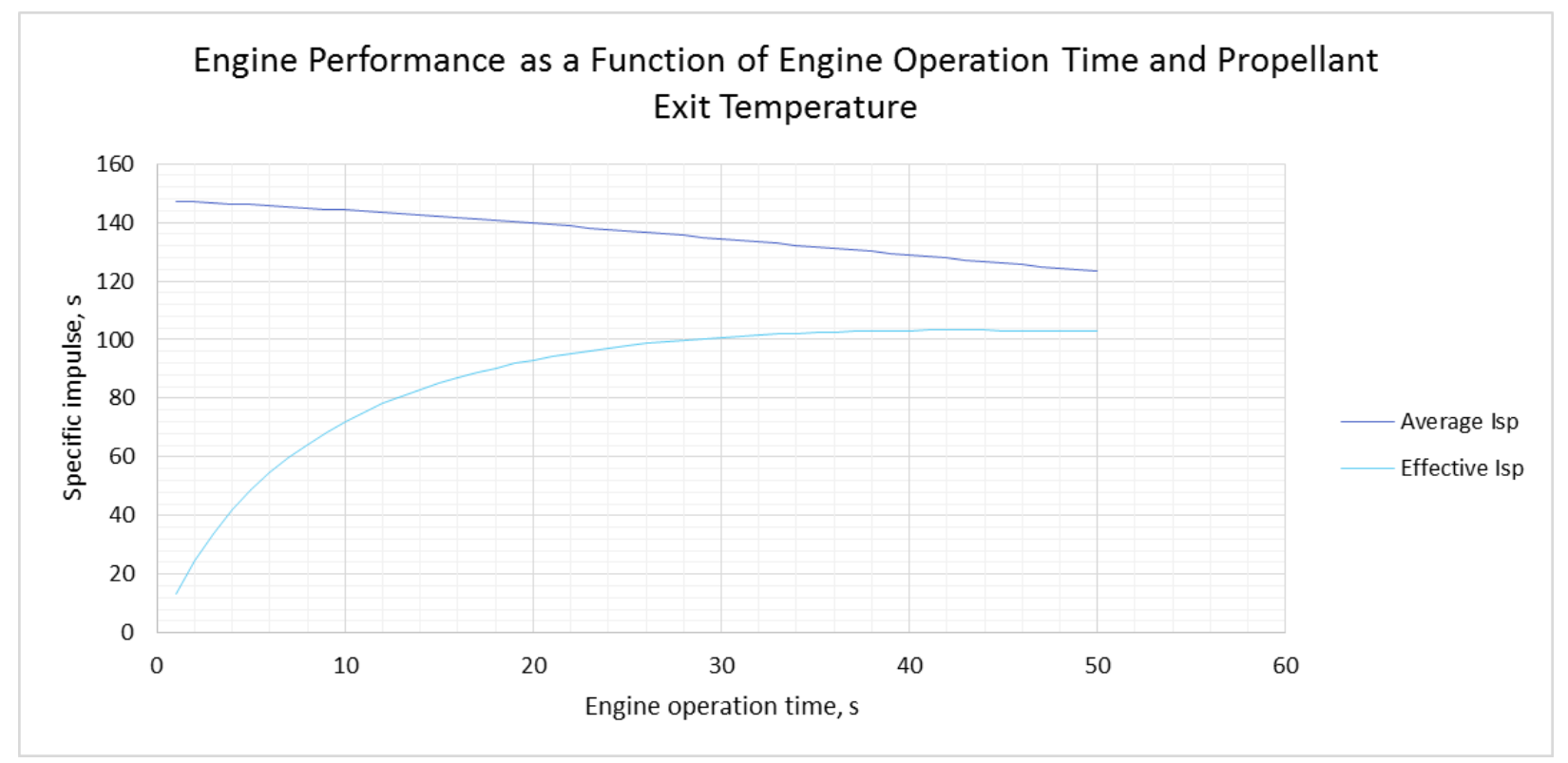

Figure 15. Engine performance as a function of engine operation time for $760^{\circ} \mathrm{C}$ initial thermal block. The plot shows how the average and effective specific impulse of the engine decreases with longer engine operation time due to the decrease in the propellant exit temperature as the thermal mass cools down. Mass flow rate is $0.1 \mathrm{~kg} / \mathrm{sec}$. 


\section{Conclusions}

An analysis was done of a thermal rocket engine using a radioisotope heat source for a refuelable Triton hopper vehicle. The results obtained from the specific impulse analysis indicate that the thermal block concept provides a considerable performance increase over the current design concept using a cold gas thruster, in which the thermal energy is stored in the gas. The estimated average specific impulse of the baseline cold-gas system is $52 \mathrm{~s}$, while the average specific impulse of the thermal block concept analyzed is $157 \mathrm{~s}$. Thus, heating the gas as the engine operates results in a performance increase of $200 \%$. With the correction of the surface temperature of the thermal block, the specific impulse of the engine is reduced to $147 \mathrm{~s}$, which means the actual performance increase obtained is about $183 \%$. Additionally, the insulation and power analysis indicate that very little power is required to heat the thermal block to the operation temperature in a period of 24 days. For a lithium thermal mass, only 2.15 watts are required to heat it to $900^{\circ} \mathrm{C}$. RHUs provide 1 watt per unit, which means only 3 units are required to power the system. For the case of the lower $760^{\circ} \mathrm{C}$ surface temperature, even less power is required. The low power requirement means that the time between hops can be reduced considerably by replacing the RHUs by a GPHS unit which provides 250 watts of power. The analysis also shows that the system can be sized to meet the mass requirements of the vehicle. A more detailed analysis of the engine needs to be performed but current results indicate that the thermal block radioisotope engine provides the best performance.

\section{Acknowledgments}

The Triton Hopper design study was supported by the NASA Innovative Advanced Concepts project at NASA Headquarters.

Jonathan would like to express his appreciation to Dr. Geoffrey A. Landis for his guidance during my internship. Without his valuable assistance, this work would not have been completed. He would also like to thank Anthony Colozza for his guidance with the thermal analysis and the tank parametrics.

\section{References}

${ }^{1}$ Oleson, S.R., and Landis, G.A., COMPASS Final Report: Triton Hopper, Phase I Report to the NASA Innovative Advanced Concepts Program, NASA Glenn Research Center Report CD-2016-127, March 2016.

${ }^{2}$ Oleson, S.R., and Landis, G.A., "Triton Hopper: Exploring Neptune’s Captured Kuiper Belt Object", paper AIAA-2016-5348, AIAA Space and Astronautics Forum and Exposition 2016, Long Beach CA, Sept. 12-15 2016; http://dx.doi.org/10.2514/6.20165348

${ }^{3}$ Landis, G.A., Oleson, S.R., and the COMPASS team, "A Hopper for Exploring Neptune's Moon Triton," 15th NASA Small Bodies Assessment Group (SBAG) meeting, Johns Hopkins University Applied Physics Laboratory, Laurel, MD, June 28-30, 2016.

${ }^{4}$ Rosen, S., "Development of a radioisotope-fueled thruster for satellite propulsion," AIAA paper 72-1066, 8th Joint Propulsion Specialist Conference New Orleans, LA http://arc.aiaa.org/doi/abs/10.2514/6.1972-1066

${ }^{5}$ LeMoyne, R., "Fundamental Analysis of Radioisotope Propulsion," paper AIAA-2006-7272, AIAA Space and Astronautics Forum and Exposition 2006, San Jose CA, Sept. 19-21 2006; http://dx.doi.org/10.2514/6.2006-7272

6Lawrence, T.J., "Nuclear-Thermal-Rocket Propulsion Systems," Chapter 2, Nuclear Space Power and Propulsion Systems, C. Bruno (ed.) AIAA Progress in Astronautics and Aeronautics, pp. 31-52, 2008; http://dx.doi.org/10.2514/5.9781600860096.0031.0052

${ }^{7}$ Howe, S.D., O'Brien, R.C., Ambrosi, R.M., Gross, B., Katalenich, J., Sailer, L., Webb, J., McKay, M., Bridges, J.C. and Bannister, N.P., "The Mars Hopper: an impulse-driven, long-range, long-lived mobile platform utilizing in situ Martian resources," Proceedings of the Institution of Mechanical Engineers, Part G: Journal of Aerospace Engineering, 225(2), 2011, pp.144-153.

${ }^{8}$ Williams, H. R., R. M. Ambrosi, and N. P. Bannister. "A Mars hopping vehicle propelled by a radioisotope thermal rocket: thermofluid design and materials selection," Proceedings of the Royal Society of London A: Mathematical, Physical and Engineering Sciences. Vol. 467, No. 2129, The Royal Society, 2011.

${ }^{9}$ Chase, M.W., Davies, C.A., Downey, J.R., Frurip, D.J., McDonald, R.A., Syverud, A.N., "JANAF Thermochemicle Tables Third Edition," Journal of Physical and Chemical Data, Vol. 14, No. 1.

${ }^{10}$ Jeppson, D.W., Ballif, J.L., Yuan, W.W., and Chou, B.E., "Lithium Literature Review: Lithium's Properties and Interactions," Hanford Engineering Development Laboratory, Series: HEDL-TME 78-15, Richland, WA, April. 1978.

${ }^{11}$ Douglas, T.B., Jr., and Dever, J.L., "Lithium Fluoride: Heat Content from 0 to $900^{\circ} \mathrm{C}$, the Melting Point and Heat of Fusion," Journal of the American Chemical Society, Vol. 76, No. 19.

${ }^{12}$ Buyco, E. H., and Davis, F. E., "Specific Heat of Aluminum from Zero to Its Melting Temperature and Beyond," Journal of Chemical and Engineering Data, Vol. 15, No. 4. 
${ }^{13}$ White, J.K., and Collocott, S.J., "Heat Capacity of Reference Materials: Cu and W," Journal of Physical and Chemical Reference Data, Vol. 13, No. 4.

${ }^{14}$ Brown, C.D., Elements of Spacecraft Design, AIAA Education Series, AIAA, Virginia, 2002, Chap. 4.

${ }^{15}$ Sutton, G. P., (5 $5^{\text {th }}$ ed.), Rocket Propulsion Elements: An Introduction to the Engineering of Rockets, AIAA Education Series, John Wiley \& Sons, Inc, New York, 1986, Chap. 2.

${ }^{16}$ Çengel, Y. A., and Ghajar, A.J., ( $5^{\text {th }}$ ed.), Heat and Mass Transfer: Fundamentals \& Applications, McGraw-Hill Education, New York, 2015, Chap. 1, 2, 8.

${ }^{17}$ Millat, J., and Wakeham, W.A., "The Thermal Conductivity of Nitrogen and Carbon Monoxide in the Limit of Zero Density," Journal of Physical and Chemical Data, Vol. 18, No. 2

${ }^{18}$ Moran, M.J., Shapiro, H.N., Boettner, D.D., Bailey, M.B., (5 $5^{\text {th }}$ ed.), Fundamentals of Engineering Thermodynamics, John Wiley \& Sons, Inc, New Jersey, 2011, Chap. 2.

${ }^{19}$ McLaughlan, P. B., Forth, S.C., and Grimes-Ledesma, L.R., Composite Overwrapped Pressure Vessels, A Primer, NASA Technical Review NASA/SP-2011-573, March 2011. 